\title{
Cognitive impairment and major depressive disorder in HIV infection and cerebrospinal fluid biomarkers
}

\author{
Alteração cognitiva e desordem depressiva maior na infecção do HIV \\ e biomarcadores no líquido cefalorraquidiano
}

Sérgio Monteiro de Almeida

\begin{abstract}
Cognitive impairment and major depressive disorder (MDD) are common HIV-1 central nervous system (CNS) complications. Their frequencies in AIDS patients are $36 \%$ and $45 \%$, respectively. The diagnoses of HIV cognitive impairment are made by clinical criteria, no single laboratory test or biomarker establishes the diagnosis. Factors of indirect neuronal injury related with the pathophysiology of the HIV infection in the CNS, are the factors studied as biomarkers. In the present no biomarker is established to the diagnosis of HIV cognitive impairment, much still needs to be done. We review in this paper some biomarkers in cerebrospinal fluid that could be valuable to the diagnosis of HIV cognitive impairment. Diagnosing depression in the context of HIV can be challenging, to identify a biomarker that could help in the diagnosis would be very important, although MDD risks and neurobiology are still poorly understood.
\end{abstract}

Keywords: HIV dementia, major depressive disorder, central nervous system, HIV, cerebrospinal fluid, biomarkers.

RESUMO

A alteração cognitiva e a desordem depressiva maior (MDD) são complicações comuns da AIDS no sistema nervoso central (CNS). Suas frequências, em pacientes com AIDS são 36 \% e $45 \%$, respectivamente. 0 diagnósticos de alteração cognitiva pelo HIV é feito por critérios clínicos, não há nenhum teste único de laboratório ou biomarcador que estabeleçam o diagnóstico. Os fatores inflamatórios relacionados com dano neuronal indireto e com a patofisiologia da infecção do HIV no CNS, são os fatores estudados como biomarcadores. No presente nenhum biomarcador é estabelecido para o diagnóstico de alteração cognitiva pelo HIV, muito ainda tem para ser feito. Nesta revisão abordaremos alguns biomarcadores no líquido cefalorraquidiano que podem auxiliar no diagnóstico da alteração cognitiva e HIV. Da mesma forma o diagnostico de depressão no contexto da aids pode ser desafiante, identificar um biomarcador que possa ajudar no diagnóstico seria muito importante, embora os riscos de desenvolvimento de MDD e a neurobiologia ainda sejam pobremente entendidos.

Palavras-Chave: HIV demência, desordem depressiva maior, sistema nervoso central, HIV, líquido cefalorraquidiano, biomarcadores.

Initial neurological interest in HIV infection was focused on opportunistic infections and tumors that affect the CNS. At that time, the CNS was considered to be only indirectly involved in the progression of HIV disease. Today we know that the CNS and the immune system are major targets of HIV infection. HIV penetrates the CNS in an initial phase of the infection; during this period the viral load in the peripheral blood is as high as it is in the terminal phase of the illness ${ }^{1}$.

Two types of CNS cells can be infected by HIV: cells derived from monocytes (microglia and macrophages) and astrocytes. These cells differ from other HIV-infected cells in some biological aspects, particularly in the way they express
HIV products. The CD4 cell surface receptor and the receptors of chemokines CCR5 and CCR3 are involved in the penetration of HIV in the cells of the microglia. The microglia developes a productive infection, leading to syncytial formation and cell death. However, the possibility of chronic infection also exists. Astrocytes are infected predominantly by lymphotropic strains, but infections with monocytotropic strains have also been described. Currently, the entrance mechanism of HIV into astrocytes remains unknown. It has been clearly shown that astrocytes do not have CD4 receptors on their surface; chemokine receptors involved in HIV infection are also not expressed. Some authors suggest that CXCR4 can be expressed following the activation of astrocytes ${ }^{2,3}$. 


\section{HIV cognitive impairment}

Human immunodeficiency virus-type 1 (HIV-1) infection is the most common preventable and treatable cause of neurocognitive impairment in individuals under age $50^{4}$. The frequency of neurocognitive impairment in recent studies, in the post HAART era in AIDS patients is $36 \%$. Due to changes in diagnosis and clinical management, HIV/AIDS, which was once an almost always fatal disease, has become, at least in those countries where ARV (antiretroviral) therapy is available, a chronic disease requiring long term care. The survival rate has greatly improved for patients with dementia ${ }^{4}$. The appearance of dementia in persons whose CD4 counts have rebounded with ARV has suggested that the CNS is not being treated as effectively as the lymphatic tissues. Diagnosis of HIV cognitive impairment is made by clinical criteria, after exclusion of other potential causes. No single laboratory test or biomarker establishes the diagnosis ${ }^{5}$. The classification of HIV cognitive impairment was reviewed in $2007^{6}$.

When available, neuropsychological (NP) testing is very helpful in diagnosis ${ }^{4}$. It provides clear documentation of cognitive impairment, and it assists in differentiating HIV dementia from other disorders that may cause impairment. Such tests should be administered by an experienced examiner, and interpreted by comparison to normative data with appropriate demographic corrections, including age, gender, education, and in some cases, ethnicity. The influence of premorbid conditions, including previous head trauma, learning disability, as well as the effects of systemic illness and substance abuse need to be considered carefully when interpreting results from NP testing.

\section{Major depression and HIV infection}

Major depressive disorder (MDD) is among the most prevalent neuropsychiatric disorders in HIV infection, affecting up to $45 \%$ at some stage of the illness, but its risks and neurobiology are poorly understood. Diagnosing depression in the context of HIV can be challenging, because symptoms may be attributable to either morbidity. The nature of the association between MDD and HIV is a matter of debate, with some suggesting that depression is simply one manifestation of HIV brain disease, whereas others consider MDD to be a primary disorder that may be exacerbated by HIV. Another theory suggests that depression may represent an adjustment reaction to the diagnosis of HIV infection. Research has not yet provided a consensus as to whether MDD may be an initial manifestation of a cerebral disorder caused by HIV infection.

\section{Mechanisms of CNS injury}

As neurons do not have CD4 cell surface receptors, they are not directly infected by HIV. The presence of HIV in the CNS is necessary but not sufficient by itself to develop cognitive impairment ${ }^{6}$. Neuronal injury occurs by indirect mechanisms of neurotoxicity as those caused by virus proteins (gp120, gp 41, tat, nef), macrophages factors, cytokines (TNF- alpha, IL-1, IL-6, GM-CSF, IFN), chemokines (MCP-1, MCP-2, MCP-3, RANTES, MIP-1 $\alpha$, MIP-1 $\beta$ ) and neurotrophic factors. HIV proteins can mimic body proteins leading to autoimmunity (gp 41; antibodies for astrocytes, anti-brain antibodies, anti-ganglioside antibodies). Also, BBB disruption may facilitate the penetration of neurotoxins from systemic infection into the brain ${ }^{7.8}$.

Neurotoxicity is not necessarily induced by long and continuous exposition to viral proteins. Transitory exposition can be enough to start a cascade of events that result in neuronal damage. These viral proteins, once available in the extracellular space, can cause neurotoxicity by direct action on the neuronal cell, or they can activate the glial cells, allowing the viral proteins to amplify their potential neurotoxicity and causing damage at a distance. Moreover, the viral proteins can act in sinergy with another neurotoxic substance, such as glutamate, to cause neurotoxicity. Acting in this way, sublevels of viral or cellular toxins could summate resulting in neuronal injury ${ }^{7,8}$.

These factors of indirect neuronal impairment related with the pathophysiology of the HIV infection in the CNS, are the factors searched as biomarkers for the management of patients with cognitive impairment in HIV infection. However, at the present much still needs to be done.

There several interactions of other HIV proteins and neuronal function. Viral envelop protein gp120 interacts with neurons and can lead to neuronal death. Gp41 can induce MMPs activity in neuronal culture. In addition, it stimulates the release of glutamate from astrocytes?.

Trans-activator of transcription (Tat) is the only protein actively secreted by HIV-1 infected cells by means of an energy dependent process. It circulates in the blood at high levels during HIV infection and can cross BBB, and large quantities of this protein enter the CNS. Tat can depolarize neurons through direct interaction with the membranes of these cells, can act like substrate to adhesion and induce aggregation of neural cultures ${ }^{10}$. Tat has a strong monocyte chemotactic property. It acts like a chemokine itself and/or indirectly through monocyte chemotactic protein 1 (MCP-1) currently classified as CCL2- secreted by astrocytes, the most numerous cells in the central nervous system and that are in close contact with BBB. Tat induces TNF- $\alpha$ release by macrophages and it has an important role in HIV infection pathogeneses. TNF- $\alpha$ is a mediator of CNS inflammatory events. It activates microglia cells, monocytes and macrophages. It is a potent inductor of inflammatory response and can stimulate an increase in MCP-1, inflammatory cytokines, ICAM1, VCAM-1 expression. Also, it can act like a chemoattractive factor, though its chemotactic response is smaller than MCP- $1^{11}$. Tat chronic production in brain causes significant alteration in inflammation histological markers and in the 
infected individual's behavior ${ }^{12}$. Other HIV proteins, like nef and rev, have a role in BBB rupture, inducing neurotoxicity ${ }^{10}$.

\section{Biomarkers}

\section{Viral load of HIV in the CSF}

The clinical importance of viral load determination in the CSF is to monitor the therapeutic effect of HAART, to identify patients with CNS escape, distinguishing diagnosis with psychiatric symptoms ${ }^{13}$.

During primary HIV infection in the peripheral blood, there is no relationship between viral load and neurological symptoms ${ }^{14}$. This is not true however, in the CSF, where higher viral load is related to neurological symptoms. Also, patients without neurological symptoms were found to have a significantly decreased viral load in the CSF, compared to the blood ${ }^{15}$.

Among patients with $\mathrm{CD} 4+>200$ cells $/ \mu \mathrm{L}$, viral load in the CSF is positively correlated with the viral load in blood, but it is not correlated with neurological alterations. After the institution of HAART, patient viral load decreases in the CSF in parallel with blood levels. Among patients with CD4+ $<200$ cells/ $\mu \mathrm{L}$, viral load in the CSF correlates with the neurological alterations. However, there is no correlation between the viral load in the CSF and the viral load in the peripheral blood; after HAART there is a slower decrease in CSF viral load in comparison to blood ${ }^{16}$.

\section{Chemokines}

Chemokines and their receptors have a central role in the interactions between HIV and the host. In the normal host, chemokines regulate immunological functions, such as chemotaxis, cellular activation and the expression of receptors. Chemokine receptors allow HIV to enter and infect susceptible cells, and their deregulation contributes to the immunological loss that occurs in AIDS. Finally, because chemokine receptors are present in neurons and glia, potentially transmitting signals between brain cells, they can either directly or indirectly produce neuronal damage ${ }^{17}$.

Chemokines, including MCP-1, also known as CCL2, are low molecular weight cytokines expressed by a wide variety of cell types including immune, endothelial and neural cells. They help to control trafficking of monocytes, T lymphocytes and natural killer cells in physiological immunologic surveillance. Their diffusion from sites of inflammation creates a chemical gradient mediating chemotaxis and creating an accumulation of these cells in inflamed tissues, including the $\mathrm{CNS}^{18}$. Chemokines also have a role in the modulation of receptor expression, cellular activation state, and cell-to-cell communication. Examination of their role is particularly important in infectious diseases such as HIV.

MCP-1 accumulates in the CSF of HAD (HIV associated dementia) patients and its level correlates with the degree of dementia. The relationship between MCP-1 level and viral load in CSF suggests that it is co-regulated or that one is a potent stimulus to the other. MCP-1 probably regulates CSF viral load because changes in MCP-1 levels occurred before or concomitantly to changes in CSF viral load ${ }^{19}$.

MCP-1 appears to play a central, if not directly causal role in HIV dementia and encephalitis. In vitro, MCP-1 mediates trafficking of infected macrophages across blood brain barrier models ${ }^{18}$, suggesting that MCP-1 is important for viral entry into the CNS. Furthermore, MCP-1 can alter the expression of chemokine receptors that serve as co-factors for entry into host cells ${ }^{20}$. Polymorphisms in the genes encoding MCP1 and its receptor, CCR2, confer an elevated risk of neurocognitive impairment in $\mathrm{HIV}^{21}$. Together, these findings suggest that it may be possible to influence the initiation and progression of HIV neurological disease by altering CNS MCP-1 expression. Our findings on the dynamics of MCP-1 production in the CNS should assist in identifying such a strategy.

\section{Beta2-microglobulin and neopterin}

Molecular markers, such as Beta2-microglobulin, quinolinic acid, and neopterin in CSF are not sufficiently sensitive or specific to assist in clinical diagnosis. Some immunological activation markers, such as neopterin, Beta2 microglobulin, quinolonic acid, PGE2, and PAF, studied in CSF, could help in the diagnosis, mainly neopterin and Beta-2 microglobulin, although they are not used routinely ${ }^{22}$. Other proteins as neurofilament light protein have also been studied ${ }^{23}$.

CSF levels of neopterin is higher in the groups who have undergone successful ARV therapy and in the group on HAART, than the control group without HIV, indicating chronic macrophage activation ${ }^{22}$. The non-penetration of ARV in the CNS contributes to the persistent neurocognitive deficit, by allowing slow viral replication in the CNS.

\section{MMPS}

Matrix metalloproteinases (MMPs) are a family of neutral proteinases that are important in normal development and have been implicated in many pathological processes, including neuroinflammation. MMPs can weaken the basal membrane, facilitating the migration of leukocytes across the BBB. The disrupted BBB during HIV infection allows free particles and infected monocytes to penetrate into the CNS. These cells can enter through tight junctions or through the endothelial cells of the capillaries, with the latter being more likely than the former. In addition to this, higher levels of matrix metalloproteinases (MMPs) in the CNS have been found ${ }^{24}$. HIV-1 infected monocytes show an increase in adhesion in endothelial and astrocyte cell cultures. It has been shown that HIV Tat protein activates endothelial cells, resulting in an increase of the expression of adhesion molecules, MMPs and cytokines. This results in the CNS serving as an important reservoir of HIV infection ${ }^{25}$. 


\section{CONCLUSIONS}

In the present no biomarker studied is established to the diagnosis of HIV cognitive impairment and much still needs to be done. There are several unanswered questions regarding the relationship between HIV infection and the CNS mainly about the importance and understanding of the CSF biomarkers:

1. The increase of the prevalence of HIV infection in patients with age higher than 65 years old; the increase of life expectancy after HAART and the fact that a striking number of HIV patients are living longer but getting older faster showing early signs of degenerative diseases usually seen in the elderly makes important the study of aging biomarkers used in the diagnosis of Alzheimer disease in HIV infection ${ }^{26}$.

2. The persistence of the inflammatory stimulus in the CNS after the control of systemic or CNS HIV infection.

3. CNS immune reconstitution inflammatory syndrome (IRIS), occurs in $0.9 \%$ and a biomarker that could help in the diagnosis would be very useful.

4. The definition of a biomarker that could help in the diagnosis and understanding of MDD in HIV infection.

\section{References}

1. Resnick L, Berger JR, Shapshak P, Tourtellotte WW. Early penetration of the blood brain barrier by HIV. Neurology 1988;38:9-14.

2. Gabuzda D, He J, Ohagen A, Vallat AV. Chemokine receptors in HIV1 infection of the central nervous system. Sem Immunol 1998;10: 203-13.

3. Schnell G, Joseph S, Spudich S, Price RW, Swanstrom R. HIV-1 replication in the central nervous system occurs in two distinct cell types. PLoS Pathog 2010;7:e1002286.

4. Heaton RK, Clifford DB, Franklin DRJ, et al. HIV-associated neurocognitive disorders persist in the era of potent antiretroviral therapy: CHARTER Study. Neurology 2010;75:2087-2096.

5. Brew BJ, Letendre SL. Biomarkers of HIV related central nervous system disease. Internat Rev Psychiatry 2008;20:73-88.

6. Antinori A, Arendt G, Becker JT, et al. Updated research nosology for HIV-associated neurocognitive disorders. Neurology 2007;69: 1789-1799.

7. Patel CA, Mukhtar M, Pomerantz RJ. Human immunodeficiency virus type $1 \mathrm{Vpr}$ induces apoptosis in human neuronal cells. J Virol 2000;74:9717-9726.

8. Power C, Kong PA, Crawford TO, et al. Cerebral white matter changes in acquired immunodeficiency syndrome dementia: alterations of the blood brain barrier. Ann Neurol 1993;34:339-350.

9. Van de Bovenkamp M, Nottet HSLM, Pereira CF. Interactions of human immunodeficiency virus-1 proteins with neurons: possible role in the development of human immunodeficiency virus-1-associated dementia. Eur J Clin Investig 2002;32:619-627.

10. Nath A. Human immunodeficiency virus (HIV) proteins in neuropathogenesis of HIV dementia. J Infect Dis 2002;186(Suppl): S193-S198.

11. Pu H, Tian J, Flora G, et al. HIV-1 Tat protein upregulates inflammatory mediators and induces monocyte invasion into the brain. Mol Cell Neurosci 2003;24:224-237.

12. Bruce-Keller AJ, Chauhan A, Dilmayuga FO, Gee J, Keller JN, Nath A. Synaptic transport of human immunodeficiency virus-Tat protein causes neurotoxicity and gliosis in rat brain. J Neurosci 2003; 23:8417-8422.

13. Tyler KL, McArthur JC. Through a glass, darkly: cerebrospinal fluid viral load measurements and the pathogenesis of human immunodeficiency virus infection of the central nervous system. Arch Neurol 2002;59:909-912

14. Stingele K, Haas J, Zimmermann T, et al. Independent HIV replication in paired CSF and blood viral isolates during antiretroviral therapy. Neurology 2001;56:355-361.

15. Tambussi G, Gori A, Capiluppi B, et al. Neurological symptoms during primary human immunodeficiency virus (HIV) infection correlate with high levels of HIV RNA in cerebrospinal fluid. Clin Infect Dis 2000:30:962-965

16. Ellis RJ,Moore DJ,Childers ME,etal.Progression to neuropsychological impairment in Human immunodeficiency virus infection predicted by elevated cerebrospinal fluid levels of Human Immunodeficiency virus RNA. Arch Neurol 2002;59:923-928.

17. Letendre SL, Lanier ER, McCutchan JA. Cerebrospinal fluid beta chemokine concentrations in neurocognitively impaired individuals infected with human immunodeficiency virus type 1. J Infect Dis 1999;180:310-319.

18. Biber K, Zuurman MW, Dijkstra IM, Boddeke HW. Chemokines in the brain: neuroimmunology and beyond. Curr Opin Pharmacol 2002:2:63-68.

19. de Almeida SM, Letendre S, Zimmerman J, Lazzaretto D, MsCutchan A, Ellis R. Dynamics of monocyte chemoattractant protein type one (MCP-1) and HIV viral load in human cerebrospinal fluid and plasma. J Neuroimmunol 2005;169:144-152.

20. Zheng J, Thylin MR, Ghorpade A, et al. Intracellular CXCR4 signaling, neuronal apoptosis and neuropathogenic mechanisms of HIV-1associated dementia.J Neuroimmunol 1999; 98:185-200.

21. Gonzalez E, Rovin BH, Sen L, et al. HIV-1 infection and AIDS dementia are influenced by a mutant MCP-1 allele linked to increased monocyte infiltration of tissues and MCP-1 levels. Proc Nat Acad Sci USA 2002;99:13795-13800.

22. Hagberg L, Cinque P, Gisslen M, et al. Cerebrospinal fluid neopterin: an informative biomarker of central nervous system immune activation in HIV-1 infection. AIDS Res Ther 2010;3:15.

23. Gisslen M, Hagberg L, Brew BJ, Cinque P, Price RW, Rosengren L. Elevated cerebrospinal fluid neurofilament light protein concentrations predict the development of AIDS dementia complex. $\mathrm{J}$ Infect Dis 2007;195:1774-1778.

24. Cross AK, Woodroofe MN. Chemokine modulation of matrix metalloproteinases and TIMP production in adult rat brain microglia and a human microglial cell line in vitro. Glia 1999;28:183-189.

25. Price RW. The two faces of HIV infection of cerebrospinal fluid. Trends in Microbiology 2000;8:387-390.

26. Gisslén M, Krut J, Andreasson U, et al. Amyloid and tau cerebrospinal fluid biomarkers in HIV infection. BMC Neurology 2009;9:63. 